\title{
Engagement in primary health care among marginalized people who use drugs in Ottawa, Canada
}

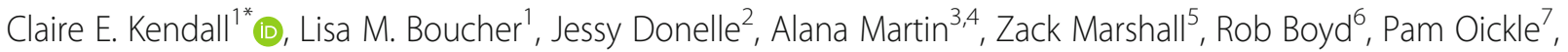
Nicola Diliso ${ }^{4}$, Dave Pineau ${ }^{4}$, Brad Renaud ${ }^{4}$, Sean LeBlanc ${ }^{4,8}$, Mark Tyndall ${ }^{9}$ and Ahmed M. Bayoumi ${ }^{10}$

\begin{abstract}
Background: There may be less primary health care engagement among people who use drugs (PWUD) than among the general population, even though the former have greater comorbidity and more frequent use of emergency department care. We investigated factors associated with primary care engagement among PWUD.

Methods: The Participatory Research in Ottawa: Understanding Drugs (PROUD) cohort study meaningfully engaged and trained people with lived experience to recruit and survey marginalized PWUD between March-December 2013. We linked this survey data to provincial-level administrative databases held at ICES. We categorized engagement in primary care over the 2 years prior to survey completion as: not engaged ( $<3$ outpatient visits to the same family physician) versus engaged in care ( $3+$ visits to the same family physician). We used multivariable logistic regression to determine factors associated with engagement in primary care.
\end{abstract}

Results: Characteristics of 663 participants included a median age of 43 years, $76 \%$ men, and $67 \%$ living in the two lowest income quintile neighborhoods. Despite high comorbidity and a median of 4 (interquartile range 0-10) primary care visits in the year prior to survey completion, only 372 (56.1\%) were engaged in primary care. Engagement was most strongly associated with the following factors: receiving provincial benefits, including disability payments (adjusted odds ratio [AOR] 4.14 (95\% confidence interval [CI] 2.30 to 7.43)) or income assistance (AOR 3.69 (95\% Cl 2.00 to 6.81)), having ever taken methadone (AOR 3.82 (95\% $\mathrm{Cl} 2.28$ to 6.41$)$ ), mental health comorbidity (AOR 3.43 ( $95 \% \mathrm{Cl} 2.19$ to 5.38)), and having stable housing (AOR 2.09 (95\% Cl 1.29 to 3.38)).

Conclusions: Despite high comorbidity, engagement in primary care among PWUD was low. Our findings suggest that social care (housing, disability, and income support) and mental health care are associated with improved primary care continuity; integration of these care systems with primary care and opioid substitution therapy may lessen the significant morbidity and acute care use among PWUD.

Keywords: People who use drugs, Primary care, Health administrative data

\footnotetext{
* Correspondence: ckendall@uottawa.ca

Brad Renaud is deceased.

${ }^{1}$ Bruyère Research Institute, 43 Bruyère Street, Annex E, Ottawa, Ontario K1N

5C8, Canada

Full list of author information is available at the end of the article
}

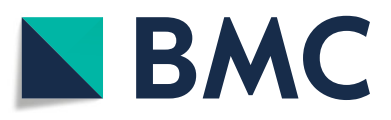

(c) The Author(s). 2020 Open Access This article is licensed under a Creative Commons Attribution 4.0 International License, which permits use, sharing, adaptation, distribution and reproduction in any medium or format, as long as you give appropriate credit to the original author(s) and the source, provide a link to the Creative Commons licence, and indicate if changes were made. The images or other third party material in this article are included in the article's Creative Commons licence, unless indicated otherwise in a credit line to the material. If material is not included in the article's Creative Commons licence and your intended use is not permitted by statutory regulation or exceeds the permitted use, you will need to obtain permission directly from the copyright holder. To view a copy of this licence, visit http://creativecommons.org/licenses/by/4.0/ The Creative Commons Public Domain Dedication waiver (http://creativecommons.org/publicdomain/zero/1.0/) applies to the data made available in this article, unless otherwise stated in a credit line to the data. 


\section{Background}

People who use drugs (PWUD) experience disproportionately high comorbidity and disability $[1,2]$ as well as excess and premature mortality $[3,4]$. Common comorbidities among PWUD include mental health conditions, HIV and hepatitis $C[2,5,6]$. Despite this high burden of illness, the large majority of people who use drugs have unmet health needs [7-9]. In turn, PWUD have disproportionately greater use of acute care services, including emergency department visits and hospital admissions for issues including mental health and substance use diagnoses, and also infectious complications such as soft tissue infections and pneumonia $[2,10,11]$.

There is strong evidence that care for complex populations is most effectively and equitably provided in well-supported primary care settings [12-15]. In contrast to other populations, where frequent emergency department visits correlate with poor access to primary care, PWUD typically have both high emergency department visit rates and frequent contacts with primary care providers [2, 10, 16]. However, frequency of contact may not be the best measure of primary care engagement, particularly if individuals do not have continuous access to the same doctor over time. For example, we have found that for PWUD, compared to not having a regular family physician, having a regular family physician reduces the odds of having multiple emergency department visits by $50 \%$ [2]. This is consistent with a broad literature evidence base demonstrating patient-reported health outcomes and health system improvements associated with having a regular source of primary care, especially for complex populations [17-19].

The objective of this study was to describe regular engagement in primary care and variables associated with this engagement among a cohort of PWUD in Ontario, Canada. We hypothesized that many PWUD would not be receiving regular care from one family physician and that multiple factors would be associated with having a regular family physician [20]. We used data from the Participatory Research in Ottawa: Understanding Drugs (PROUD) study [21], a community-based study of marginalized PWUD in Ottawa who participated in survey design, administration, and analysis. We linked PROUD data to provincial administrative databases, creating a unique dataset with rich individual-level information about health services use within a single payer system with universal access to physician services.

\section{Methods}

\section{Theoretical influences}

To define our variable selection, we were guided by the Rhodes' 'Risk Environment Framework' [20, 22]. Focusing on the HIV risk environment among PWUD, this framework was used in designing the PROUD study protocol, including creation of the survey tool [21]. It was also incorporated in previous analysis of the survey data [23], as well as in a qualitative sub-study conducted by the PROUD team [24]. In the present study, our selection process with the study's Community Advisory Committee aimed to include variables that represent several different risk environments (i.e. social, economic, physical, policy).

\section{Data sources}

PROUD cohort study: As described previously [21], the PROUD study used street-based peer recruitment and a snowball sampling approach to enrol participants who completed a cross-sectional survey. Our focus was on socially and economically marginalized PWUD. Eligibility criteria included being 16 years of age or older and reporting having injected or smoked drugs other than marijuana in the 12 months prior to enrolment (March to December 2013). Participants completed a peer- or medical student-administered survey that included questions about socio-demographic information, substance use, environmental-structural factors (e.g., legal issues, housing), interpersonal relationships (e.g., connection to community, sexual history), harm reduction practices, health status, and health and social services use. All PROUD study activities were governed by a Community Advisory Committee of PWUD and allies.

ICES databases: For consenting PROUD participants, additional data were obtained by linking the survey responses with health administrative databases held at ICES (www.ices.on.ca). ICES datasets use unique encoded identifiers and are analyzed at ICES. We linked data from PROUD participants deterministically using these identifiers based on participants' reported Ontario Health Insurance Plan (OHIP) numbers if available, or probabilistically based on their names, dates of birth, and postal codes. We identified participants with duplicate enrolment following linkage and retained responses with the most complete data.

We used the following ICES databases for our study: the Registered Persons database, to obtain demographic data for all residents eligible for provincial health care; the Discharge Abstract Database, to identify all provincial hospital admission and discharge data; the National Ambulatory Care Reporting System, to obtain encounter-level information on visits to emergency departments, including discharge diagnoses; the 2006 Statistics Canada Census data, to estimate socioeconomic status by attributing an income quintile by linking postal code of residence to the mean household income by dissemination area, which represents a standard geographic area typically consisting of 400 to 700 individuals; and the Ontario Drug Benefits, to identify prescription claims by individuals age 65 or older or those 
Table 1 Baseline Characteristics of PROUD participants

\begin{tabular}{|c|c|}
\hline Variable & $N=663$ \\
\hline Demographic characteristics & n (\%) \\
\hline \multicolumn{2}{|l|}{ Age } \\
\hline Mean (SD) & $41.4(10.8)$ \\
\hline Median (IQR) & $43(33-50)$ \\
\hline \multicolumn{2}{|l|}{ Age category (years) } \\
\hline$<=24$ & $54(8.1 \%)$ \\
\hline 25 to 34 & $134(20.2 \%)$ \\
\hline 35 to 44 & $182(27.5 \%)$ \\
\hline $45+$ & $293(44.2 \%)$ \\
\hline \multicolumn{2}{|l|}{ Gender } \\
\hline Male & $501(75.6 \%)$ \\
\hline Female & $162(24.4 \%)$ \\
\hline \multicolumn{2}{|l|}{ Ethnicity } \\
\hline Indigenous only ${ }^{\mathrm{a}}$ & $120(18.1 \%)$ \\
\hline Other/no answer & $543(81.9 \%)$ \\
\hline \multicolumn{2}{|l|}{ First language } \\
\hline French & $102(15.4 \%)$ \\
\hline English & $512(77.2 \%)$ \\
\hline Other/no answer & $49(7.4 \%)$ \\
\hline \multicolumn{2}{|l|}{ Sexual orientation } \\
\hline Heterosexual & $587(88.5 \%)$ \\
\hline Gay/lesbian/homosexual/other & $76(11.5 \%)$ \\
\hline \multicolumn{2}{|l|}{ Neighborhood of residence } \\
\hline Market/Lowertown & $273(41.2 \%)$ \\
\hline Centretown & $117(17.6 \%)$ \\
\hline Other & $273(41.2 \%)$ \\
\hline \multicolumn{2}{|l|}{ Neighborhood Income Quintile } \\
\hline 1 (lowest) & $246(37.1 \%)$ \\
\hline 2 & $196(29.6 \%)$ \\
\hline 3 & $144(21.7 \%)$ \\
\hline 4 and 5 (highest) & $64(9.6 \%)$ \\
\hline Missing & $13(2.0 \%)$ \\
\hline \multicolumn{2}{|l|}{ Highest level of education } \\
\hline Some high school or less & $308(46.5 \%)$ \\
\hline High school graduate or equivalent & $193(29.1 \%)$ \\
\hline Some college or university & 99 (14.9\%) \\
\hline College or university completed & $63(9.5 \%)$ \\
\hline \multicolumn{2}{|l|}{ Provincial social assistance benefits } \\
\hline $\begin{array}{l}\text { Disability payments (Ontario Disability } \\
\text { Support Program) }\end{array}$ & $342(51.6 \%)$ \\
\hline Income assistance (Ontario Works) & $164(24.7 \%)$ \\
\hline Other (includes Trillium, 65y+, none) & $157(23.7 \%)$ \\
\hline \multicolumn{2}{|l|}{ Comorbidity } \\
\hline No comorbidity (0 ADGs) ${ }^{b}$ & $82(12.4 \%)$ \\
\hline
\end{tabular}

Table 1 Baseline Characteristics of PROUD participants (Continued)

\begin{tabular}{cl}
\hline Variable & $N=663$ \\
\hline Low comorbidity (1-5 ADGs) & $242(36.5 \%)$ \\
Medium comorbidity (6-9 ADGs) & $169(25.5 \%)$ \\
High comorbidity (> = 10 ADGs) & $170(25.6 \%)$
\end{tabular}

\section{Social characteristics}

n (\%)

Received drugs, money, gifts for sex last

$82(12.4 \%)$ 12 months

Stable housing

$248(37.4 \%)$

Ever red zoned

$212(32.0 \%)$

Detained in jail overnight or longer ever

$510(76.9 \%)$

Detained in jail overnight or longer last

$252(38.0 \%)$

12 months

Drug use characteristics

n (\%)

Ever injected drugs

$462(69.7 \%)$

Drug use in past 12 months

$$
\begin{aligned}
& \text { Any injection } \\
& \text { Non-injection use of only non-opioids }
\end{aligned}
$$

$326(49.2 \%)$

$271(40.9 \%)$

Non-injection drug use of both opioids

$390(58.8 \%)$ and non-opioids

Ever injected with used needle

185 (27.9\%)

Ever with unknown needle

$126(19.0 \%)$

Frequency of injecting with others in past 12 months

\section{Always}

$81(12.2 \%)$

Most of the time

Usually/sometimes/occasionally

$46(6.9 \%)$

$140(21.1 \%)$

Never

$54(8.1 \%)$

Other

$342(51.6 \%)$

Location of injection drug use

House/apartment

$100(15.1 \%)$

Public place

$563(84.9 \%)$

Most frequent location of injection drug use

House/apartment

$207(31.25)$

Public place

$456(68.8 \%)$

Ever overdosed

$302(45.6 \%)$

Overdosed in past 12 months

$113(17.0 \%)$

Last overdose taken to ED/hospital

$144(21.7 \%)$

\section{Health characteristics}

n (\%)

Comorbid HIV

$50(7.5 \%)$

Comorbid mental health condition (excluding substance use)

$341(51.4 \%)$

Self-reported health status

Excellent/very good

$154(23.2 \%)$

Good

$249(37.6 \%)$

Fair/poor/no answer

$260(39.2 \%)$

Ever suicidal ideation 
Table 1 Baseline Characteristics of PROUD participants (Continued)

\begin{tabular}{ll}
\hline Variable & $N=663$ \\
\hline Ever attempted suicide & $227(34.2 \%)$ \\
Attempted suicide in last 12 months & $61(9.2 \%)$ \\
Ever tested for Hepatitis C & $562(84.8 \%)$ \\
Reported last Hepatitis C test results & \\
$\quad$ Positive & $258(38.9 \%)$ \\
$\quad$ Negative & $268(40.4 \%)$ \\
$\quad$ No answer/don't know/missing & $137(20.7 \%)$ \\
Health care utilization & $\mathbf{n}(\%)$ \\
Received support from peer worker & $277(41.8 \%)$ \\
Received support from social support organization & $402(60.6 \%)$ \\
Have a regular doctor & $373(56.2 \%)$ \\
Been to a health clinic/doctor office/walk-in & $399(60.2 \%)$ \\
in past 12 months & \\
\# of outpatient primary care visits in 1 year & \\
prior to survey completion & \\
$\quad$ Mean (SD) & $9.9(16.8)$ \\
Median (IQR) & $4(0-10)$ \\
Care engagement & \\
Engaged in primary care & $239(36.0 \%)$ \\
Not engaged in primary care & $372(56.1 \%)$ \\
Ever on methadone & $291(43.8 \%)$ \\
Currently on methadone & $223(33.6 \%)$ \\
\hline
\end{tabular}

"Although" Aboriginal" was the language used in the survey, we use "Indigenous" in this text to reflect current preference

${ }^{\mathrm{b}} \mathrm{ADGs}=$ Aggregated Diagnosis Groups

receiving income assistance (Ontario Works), disability payments (Ontario Disability Support Program), or provincially-subsidized catastrophic drug coverage (Trillium). We included three databases to capture the distinct ways in which primary care is delivered in Ontario: the OHIP billing claims system, which captures fee-for-service physician services provided in the province; the Community Health Centre database, to identify encounter information for patients seen in Ontario's Community Health Centres; and the Client Agency Program Enrolment Registry, which compiles encounters for patients who are rostered to family physicians.

\section{Variables}

In general, we used administrative data for variables associated with health care and medication use and most diagnoses and PROUD survey data for other variables, including those that are not captured in administrative records. We categorized gender using self-reported gender in the PROUD survey except when gender was missing or when participants reported gender as "two- spirited" or "other", in which case we used ICES data (sex at birth). We excluded transgender individuals due to the risk of re-identification ( $<6$ participants). We used postal code to assign neighbourhood income into quintiles. We classified comorbidity using the Johns Hopkins Adjusted Clinical Groups Case-Mix Assignment software (Sun Microsystems Inc., Santa Clara, CA) by assigning up to 32 distinct Aggregated Diagnosis Groups (ADGs) based on condition duration, severity, diagnostic certainty, etiology, and specialty care involvement (www.hopkinsacg.org) [25]. We categorized comorbidity as low ( $\leq 5$ ADGs), medium (6-9 ADGs), or high ( $\geq 10$ ADGs). We used validated ICES algorithms to classify the prevalence of mental health conditions and HIV, and have included these algorithms in Appendix in Table 4 [26, 27]. We calculated primary care visits from the OHIP and Community Health Centre databases.

\section{Outcomes}

Our primary outcome was engagement in primary care, which we defined as 3 or more visits to the same family physician in the 2 years prior to PROUD survey completion [28]. For this assignment, we excluded visits that physician billing claims indicated were primarily for opioid substitution therapy, since in our setting such visits are not usually directed towards comprehensive primary care (we did include such visits in a sensitivity analysis). Engagement was categorized irrespective of the model of primary care; that is, if a patient was contractually rostered to one family physician but had at least 3 visits and the majority of their primary care visits elsewhere, they would be assigned as engaged in care with the physician they saw most frequently.

\section{Analyses}

We used descriptive statistics to summarize our cohort, stratified by primary care engagement category, including measures of central tendencies and dispersion. We compared engagement status using Wilcoxon rank sum tests for continuous variables and chi squared tests or Fisher's exact test as appropriate for categorical variables. We used logistic regression to analyze variables associated with primary care engagement. We used a non-parsimonious approach and Community Advisory Committee input to selecting covariates but excluded those that we judged likely to be collinear to avoid overfitting the model (e.g. we removed "Detained in jail overnight or longer ever" but kept "Detained in jail overnight or longer in the last 12 months"). We removed primary care visits from our multivariable model as they are directly associated with the outcome (number of care encounters is used to determine primary care engagement status). We 
reported associations as odds ratios with 95\% confidence intervals.

For several PROUD variables, participants had response options of "no answer" or "don't know/unsure". Other variables had missing values. Our primary analyses used a complete case approach; we also conducted a sensitivity analysis in which questions with missing, "don't know/unsure", and "no answer" response categories were dichotomized (yes versus no), with the no category including any non-yes response.

We used a $p$-value threshold of 0.05 to determine statistical significance. Cell sizes of 6 or less were reported in aggregate to preserve confidentiality. SAS statistical software version 9.4 (SAS Institute Inc., Cary, N.C.) was used to conduct all statistical analyses.

This study received approval from the Ottawa Health Sciences Network Research Ethics Board (OHSN-REB $\# 20120566-01 \mathrm{H}$ ). The use of administrative data in this project was authorized under section 45 of Ontario's Personal Health Information Protection Act, which does not require review by a Research Ethics Board.

\section{Results}

Between March and December 2013, 858 PROUD participants completed the survey. Of these, 798 participants agreed to linkage to ICES, and, after we excluded duplicate enrolments and those who did not have Ontario health insurance, 663 of 782 participants (85\%) were successfully linked. Among linked participants,
$76 \%$ were men, the median age was 43 years, $67 \%$ lived in a neighbourhood in one of the two lowest income quintiles, and $76 \%$ received either disability or income assistance. Table 1 highlights further characteristics from both administrative and self-reported data. By selfreport, $56.2 \%$ had a regular doctor and $60.2 \%$ reported seeking care in a health clinic, doctor's office or walk-in clinic in the previous 12 months. By administrative data, participants had a median of 4 primary care visits (interquartile range [IQR] 0-10) in the year prior to survey completion (Fig. 1). In the year prior to survey completion, $18.3 \%$ had no primary care visits captured in administrative data.

Table 2 compares PROUD participants who were engaged in primary care $(56.1 \%)$ versus those not engaged $(43.9 \%)$. Those who were engaged in primary care were more likely to be in the lowest income quintile $(40.1 \%$ vs. $33.3 \%, p=0.02$ for comparison across all income strata), to be receiving disability payments $(64.5 \%$ vs. $35.1 \%, p<0.01)$ and to have high comorbidity $(36.8 \%$ vs. $11.3 \%, \mathrm{p}<0.01$ across all comorbidity strata). For social characteristics, people who were engaged in primary care were also more likely to report receiving drugs, money or gifts for sex the last 12 months $(15.1 \%$ vs. $8.9 \%, \mathrm{p}=0.02)$, to have stable housing ( $45.7 \%$ vs. $26.8 \%, \mathrm{p}<0.01)$, and to have been red zoned (legally barred from being within a specific geographical area for a specific period of time, often due to drug-related activity in that area)

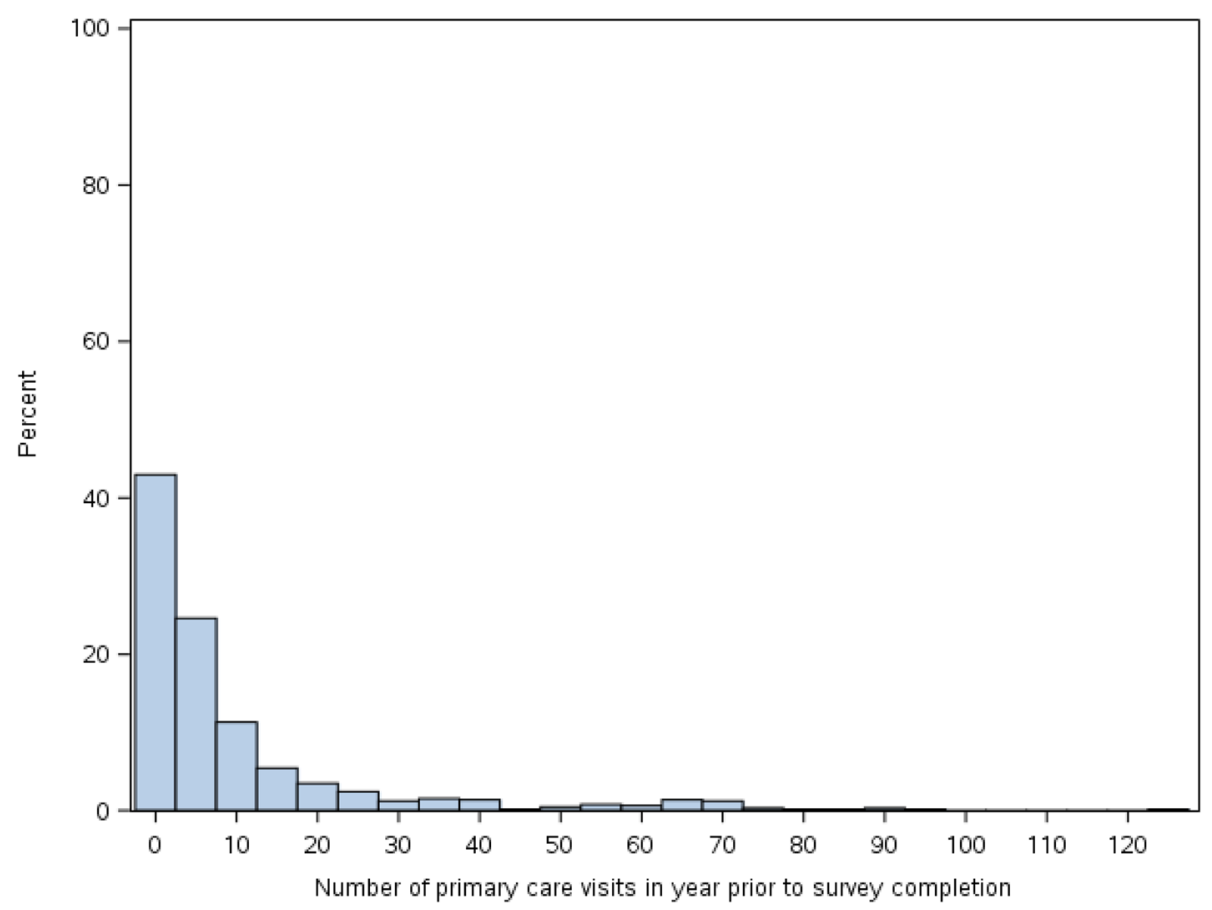

Fig. 1 Distribution of primary care visits in year prior to survey completion 
Table 2 PROUD participant characteristics by care engagement status (non-opioid substitution therapy visits) $(n=663)$

\begin{tabular}{|c|c|c|c|}
\hline \multirow[t]{2}{*}{ Variable } & \multirow{2}{*}{$\begin{array}{l}\text { Not Engaged } \\
N=291\end{array}$} & \multirow{2}{*}{$\begin{array}{l}\text { Engaged } \\
N=372\end{array}$} & \multirow[t]{2}{*}{$P$ value $^{a}$} \\
\hline & & & \\
\hline Demographic characteristics & n (\%) & n (\%) & \\
\hline \multicolumn{4}{|l|}{ Age } \\
\hline Mean (SD) & $41.3(10.6)$ & $41.6(10.9)$ & 0.734 \\
\hline Median (IQR) & $42(33-50)$ & $43(32-50)$ & 0.652 \\
\hline \multicolumn{4}{|l|}{ Age category (years) } \\
\hline$<=24$ & $26(8.9 \%)$ & $28(7.5 \%)$ & \multirow[t]{4}{*}{0.406} \\
\hline 25 to 34 & $56(19.2 \%)$ & $78(21.0 \%)$ & \\
\hline 35 to 44 & 88 (30.2\%) & $94(25.3 \%)$ & \\
\hline $45+$ & $121(41.6 \%)$ & $172(46.2 \%)$ & \\
\hline \multicolumn{4}{|l|}{ Gender } \\
\hline Male & $229(78.7 \%)$ & $272(73.1 \%)$ & \multirow[t]{2}{*}{0.097} \\
\hline Female & $62(21.3 \%)$ & $100(26.9 \%)$ & \\
\hline \multicolumn{4}{|l|}{ Ethnicity } \\
\hline Indigenous only & $59(20.3 \%)$ & $61(16.4 \%)$ & \multirow[t]{2}{*}{0.198} \\
\hline Other/no answer & $232(79.7 \%)$ & $311(83.6 \%)$ & \\
\hline \multicolumn{4}{|l|}{ First language } \\
\hline French & $48(16.5 \%)$ & $54(14.5 \%)$ & \multirow[t]{3}{*}{0.761} \\
\hline English & $221(75.9 \%)$ & $291(78.2 \%)$ & \\
\hline Other/no answer & $22(7.6 \%)$ & $27(7.3 \%)$ & \\
\hline \multicolumn{4}{|l|}{ Sexual orientation } \\
\hline Heterosexual & $263(90.4 \%)$ & $324(87.1 \%)$ & \multirow[t]{2}{*}{0.188} \\
\hline Gay/lesbian/homosexual/other & $28(9.6 \%)$ & 48 (12.9\%) & \\
\hline \multicolumn{4}{|l|}{ Neighborhood of residence } \\
\hline Market/Lowertown & $130(44.7 \%)$ & $143(38.4 \%)$ & \multirow[t]{3}{*}{0.237} \\
\hline Centretown & $46(15.8 \%)$ & $71(19.1 \%)$ & \\
\hline Other & $115(39.5 \%)$ & $158(42.5 \%)$ & \\
\hline \multicolumn{4}{|l|}{ Neighborhood Income Quintile } \\
\hline 1 (lowest) & $97(33.3 \%)$ & $149(40.1 \%)$ & \multirow[t]{5}{*}{0.002} \\
\hline 2 & $99(34.0 \%)$ & $97(26.1 \%)$ & \\
\hline 3 & $62(21.3 \%)$ & $82(22.0 \%)$ & \\
\hline 4 and 5 (highest) & $22(7.6 \%)$ & $<=45(0.0 \%)$ & \\
\hline Missing & $11(3.8 \%)$ & $<=5(0.0 \%)$ & \\
\hline \multicolumn{4}{|l|}{ Highest level of education } \\
\hline Some high school or less & $141(48.5 \%)$ & $167(44.9 \%)$ & \multirow[t]{4}{*}{0.764} \\
\hline High school graduate or equivalent & $84(28.9 \%)$ & $109(29.3 \%)$ & \\
\hline Some college or university & $41(14.1 \%)$ & $58(15.6 \%)$ & \\
\hline College or university completed & $25(8.6 \%)$ & $38(10.2 \%)$ & \\
\hline \multicolumn{4}{|l|}{ Provincial social assistance benefits } \\
\hline Disability payments (Ontario Disability Support Program) & $102(35.1 \%)$ & $240(64.5 \%)$ & \multirow[t]{3}{*}{$<.001$} \\
\hline Income assistance (Ontario Works) & $67(23.0 \%)$ & $97(26.1 \%)$ & \\
\hline Other (includes Trillium, 65y+, none) & $122(41.9 \%)$ & $35(9.4 \%)$ & \\
\hline \multicolumn{4}{|l|}{ Comorbidity } \\
\hline No comorbidity (0 ADGs) & $77(26.5 \%)$ & $<=5(0.0 \%)$ & $<.001$ \\
\hline
\end{tabular}


Table 2 PROUD participant characteristics by care engagement status (non-opioid substitution therapy visits) ( $\mathrm{n}=663)($ Continued)

\begin{tabular}{l} 
Variable \\
\hline Low comorbidity (1-5 ADGs) \\
Medium comorbidity (6-9 ADGs) \\
High comorbidity (>=10 ADGs) \\
Social characteristics \\
Received drugs, money, gifts for sex last 12 months \\
Stable housing \\
Ever red zoned \\
Detained in jail overnight or longer ever \\
Detained in jail overnight or longer last 12 months
\end{tabular}

\section{Drug use characteristics}

Ever injected drugs

Drug use in past 12 months

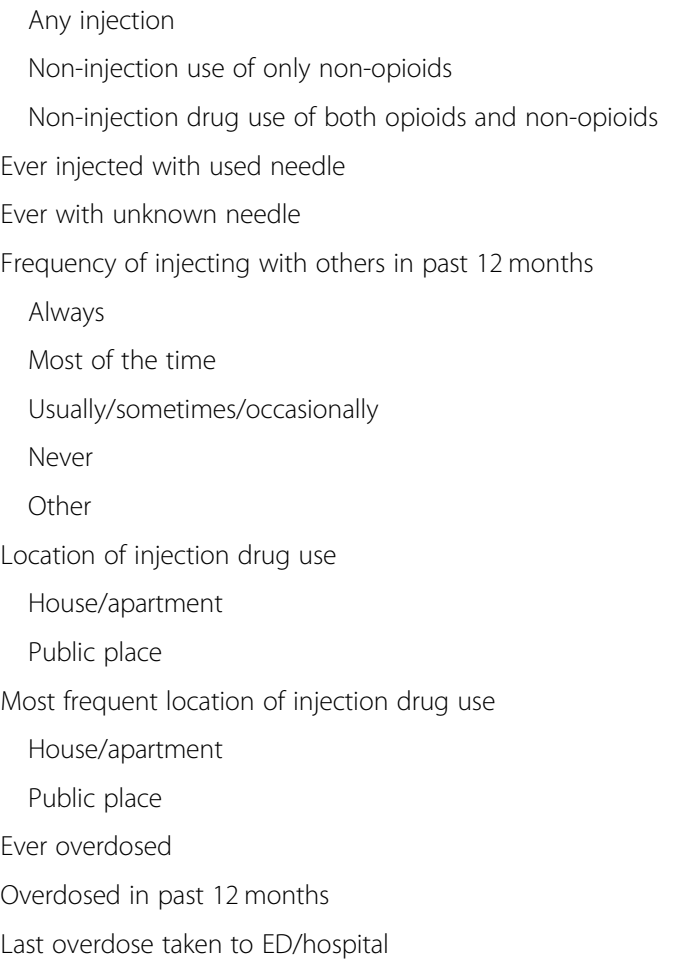

\section{Health characteristics}

\section{Comorbid HIV}

Comorbid mental health condition (excluding substance use) Self-reported health status

\footnotetext{
Excellent/very good

Good

Fair/poor/no answer

Ever suicidal ideation

Ever attempted suicide

Attempted suicide in last 12 months

Ever tested for Hepatitis $C$
}

\begin{tabular}{|c|c|c|}
\hline Not Engaged & Engaged & $P$ value \\
\hline$N=291$ & $N=372$ & \\
\hline $123(42.3 \%)$ & 119 (32.0\%) & \\
\hline 58 (19.9\%) & $<=115(0.0 \%)$ & \\
\hline 33 (11.3\%) & 137 (36.8\%) & \\
\hline n (\%) & n (\%) & \\
\hline $26(8.9 \%)$ & $56(15.1 \%)$ & 0.018 \\
\hline 78 (26.8\%) & $170(45.7 \%)$ & $<.001$ \\
\hline $80(27.5 \%)$ & $132(35.5 \%)$ & 0.029 \\
\hline $223(76.6 \%)$ & 287 (77.2\%) & 0.875 \\
\hline 105 (36.1\%) & 147 (39.5\%) & 0.366 \\
\hline n (\%) & n (\%) & \\
\hline 173 (59.5\%) & 289 (77.7\%) & $<.001$ \\
\hline 107 (36.8\%) & 219 (58.9\%) & $<.001$ \\
\hline 142 (48.8\%) & $129(34.7 \%)$ & $<.001$ \\
\hline 148 (50.9\%) & $242(65.1 \%)$ & $<.001$ \\
\hline 56 (19.2\%) & 129 (34.7\%) & $<.001$ \\
\hline $46(15.8 \%)$ & $80(21.5 \%)$ & 0.063 \\
\hline $26(8.9 \%)$ & 55 (14.8\%) & $<.001$ \\
\hline $15(5.2 \%)$ & 31 (8.3\%) & \\
\hline 40 (13.7\%) & $100(26.9 \%)$ & \\
\hline $21(7.2 \%)$ & 33 (8.9\%) & \\
\hline 189 (64.9\%) & $153(41.1 \%)$ & \\
\hline 36 (12.4\%) & $64(17.2 \%)$ & 0.084 \\
\hline 255 (87.6\%) & $308(82.8 \%)$ & \\
\hline 64 (22.0\%) & $143(38.4 \%)$ & $<.001$ \\
\hline 227 (78.0\%) & $229(61.6 \%)$ & \\
\hline 114 (39.2\%) & $188(50.5 \%)$ & 0.004 \\
\hline 44 (15.1\%) & 69 (18.5\%) & 0.244 \\
\hline 57 (19.6\%) & 87 (23.4\%) & 0.239 \\
\hline n (\%) & n (\%) & \\
\hline $12(4.1 \%)$ & $38(10.2 \%)$ & 0.003 \\
\hline 109 (37.5\%) & $253(68.0 \%)$ & $<.001$ \\
\hline 71 (24.4\%) & $83(22.3 \%)$ & 0.071 \\
\hline 120 (41.2\%) & 129 (34.7\%) & \\
\hline 100 (34.4\%) & $160(43.0 \%)$ & \\
\hline 161 (55.3\%) & 228 (61.3\%) & 0.122 \\
\hline 95 (32.6\%) & $132(35.5 \%)$ & 0.445 \\
\hline $25(8.6 \%)$ & 36 (9.7\%) & 0.631 \\
\hline 226 (77.7\%) & $336(90.3 \%)$ & $<.001$ \\
\hline
\end{tabular}


Table 2 PROUD participant characteristics by care engagement status (non-opioid substitution therapy visits) $(n=663)(C o n t i n u e d)$

\begin{tabular}{|c|c|c|c|}
\hline \multirow[t]{2}{*}{ Variable } & Not Engaged & Engaged & \multirow[t]{2}{*}{$P$ value ${ }^{a}$} \\
\hline & $N=291$ & $N=372$ & \\
\hline \multicolumn{4}{|l|}{ Reported last Hepatitis $C$ test results } \\
\hline Positive & $78(26.8 \%)$ & $180(48.4 \%)$ & \multirow[t]{3}{*}{$<.001$} \\
\hline Negative & $131(45.0 \%)$ & $137(36.8 \%)$ & \\
\hline No answer/don't know/missing & $82(28.2 \%)$ & $55(14.8 \%)$ & \\
\hline Health care utilization & n (\%) & n (\%) & \\
\hline Received support from peer worker & $121(41.6 \%)$ & $156(41.9 \%)$ & 0.927 \\
\hline Received support from social support organization & $179(61.5 \%)$ & $223(59.9 \%)$ & 0.682 \\
\hline \multicolumn{4}{|c|}{ \# of outpatient primary care visits in 1 year prior to survey completion } \\
\hline Median (IQR) & $1(0-3)$ & $8(4-19)$ & $<0.001$ \\
\hline Ever on methadone & $51(17.5 \%)$ & $172(46.2 \%)$ & $<.001$ \\
\hline Currently on methadone & $35(12.0 \%)$ & $128(34.4 \%)$ & $<.001$ \\
\hline Accessed addiction treatment in past 12 months & 102 (35.1\%) & 137 (36.8\%) & 0.636 \\
\hline
\end{tabular}

aalpha level of 0.05 used to determine statistical significance

(35.5\% vs. $27.5 \%, p=0.029)$. With respect to drug use, participants engaged in primary care were more likely to have ever injected drugs $(77.7 \%$ vs. $59.5 \%, \mathrm{p}<0.01)$. Those engaged in primary care were also more likely to have ever taken methadone $(46.2 \%$ vs. $17.5 \%, \mathrm{p}<$ 0.01 ). As expected, participants engaged in primary care had many more primary care visits in the previous year (median 8 visits vs. 1 visit, $\mathrm{p}<0.01$ ).

In our complete case adjusted analysis $(n=533)$ (Table 3), primary care engagement was associated with receiving provincial benefits, including disability payments (adjusted odds ratio [AOR] 4.14 (95\% confidence interval [CI] 2.30 to 7.43 )) or income assistance (AOR 3.69 (95\% CI 2.00 to 6.81)). Primary care engagement was also associated with having stable housing (AOR 2.09 (95\% CI 1.29 to 3.38)), having mental health comorbidity (excluding substance use disorder) (AOR 3.43 (95\% CI 2.19 to 5.38)) and reporting ever taken methadone (AOR 3.82 (95\% CI 2.28 to 6.41)).

In our sensitivity analysis that collapsed all "no answer", "don't know" and missing responses with "no", receiving drugs, money or gifts for sex in the last 12 months had a similar effect size but the confidence interval became narrower (AOR 2.02 (95\% CI 1.01 to 4.07)), and other associations from the original model persisted (Supplemental Table 1). In our sensitivity analysis that included visits exclusively for opioid substitution therapy in our categorization of engagement status (Supplemental Table 2), the same variables were associated with primary care engagement as in our primary analysis, although the effect size for each variable increased slightly.

\section{Discussion}

Despite high comorbidity and frequent primary care visits, we found primary care engagement, defined as three or more visits to the same family physician, was low among a cohort of marginalized PWUD. We found that primary care engagement was more likely among PWUD who received provincial benefits, had stable housing, had mental health comorbidity, and reported ever being on methadone.

Considering the complexity of health care needs among PWUD, the lack of recurrent visits to any individual family physician is a concern. Our previous work has shown this cohort is also less likely to receive teambased primary care compared to the broader Ontario population [29]. Expanding on Kerr et al.'s [10] finding that $78 \%$ of PWUD self-reported visits to primary care in the past year (with a median of 8 visits [IQR 3-8]), we found that only $56 \%$ of this population had regular engagement with any one family physician (with a median of 4 visits [IQR $0-10]$ ). While this may reflect lack of continuity with a single family physician, it also aligns with previous literature demonstrating that self-reported estimates of primary care use may be over-estimated compared to administrative sources [30-32].

Many of the characteristics we identified as associated with primary care engagement reflect the intersection of social locations and environmental risks experienced by PWUD [22], as well as the ways these social positions intersect to exacerbate their number of care needs $[8$, 33]. For example, people who receive disability payments, social services, and housing support likely have high mental health comorbidity [8,34]. Despite greater reported barriers to care [7], PWUD with concomitant mental health disorders may be more likely to access medical treatment and counseling services than those with substance use disorder alone, given evidence that integration of substance use disorder services lags behind that of mental health services in primary care 
Table 3 Multivariable logistic regression of PROUD participant characteristics associated with care engagement, excluding opioid substitution therapy visits, Complete case analysis ( $\mathrm{n}=$ 533)

\begin{tabular}{|c|c|}
\hline Variable & $\begin{array}{l}\text { Engaged } \mathrm{AOR}^{\mathrm{a}} \\
(95 \% \mathrm{Cl})\end{array}$ \\
\hline \multicolumn{2}{|l|}{ Demographic characteristics } \\
\hline Age & $1.00(0.98,1.02)$ \\
\hline \multicolumn{2}{|l|}{ Gender } \\
\hline Male & $1.10(0.63,1.93)$ \\
\hline Female & ref \\
\hline \multicolumn{2}{|l|}{ Ethnicity } \\
\hline Indigenous & $1.21(0.69,2.10)$ \\
\hline Other & ref \\
\hline \multicolumn{2}{|l|}{ Sexual Orientation } \\
\hline Heterosexual & $0.78(0.37,1.66)$ \\
\hline Gay/lesbian/homosexual/other & ref \\
\hline \multicolumn{2}{|l|}{ Neighborhood Income quintile } \\
\hline 1 (Lowest) & $0.55(0.24,1.26)$ \\
\hline 2 & $0.47(0.20,1.07)$ \\
\hline 3 & $0.77(0.32,1.82)$ \\
\hline 4 and 5 (Highest) & ref \\
\hline \multicolumn{2}{|l|}{ Highest level of education } \\
\hline College or university completed & $0.95(0.47,1.93)$ \\
\hline Some college or university & $0.93(0.49,1.74)$ \\
\hline High school graduate or equivalent & $1.01(0.61,1.67)$ \\
\hline Some high school or less & ref \\
\hline \multicolumn{2}{|l|}{ Provincial social assistance benefits } \\
\hline $\begin{array}{l}\text { Disability payments (Ontario Disability } \\
\text { Support Program) }\end{array}$ & $4.14(2.30,7.43)$ \\
\hline Income assistance (Ontario Works) & $3.69(2.00,6.81)$ \\
\hline Other (includes Trillium, 65y+, none) & ref \\
\hline \multicolumn{2}{|l|}{ Social characteristics } \\
\hline \multicolumn{2}{|c|}{ Received drugs, money, gifts for sex in last 12 months } \\
\hline Yes & $1.94(0.85,4.46)$ \\
\hline Other & ref \\
\hline \multicolumn{2}{|l|}{ Housing situation } \\
\hline Stable housing & $2.09(1.29,3.38)$ \\
\hline Unstable housing & ref \\
\hline \multicolumn{2}{|c|}{ Detained in jail overnight or longer in the last 12 months } \\
\hline Yes & $1.15(0.72,1.81)$ \\
\hline Other & ref \\
\hline
\end{tabular}

Ever red zoned

Yes

$1.37(0.85,2.21)$

Other

ref
Table 3 Multivariable logistic regression of PROUD participant characteristics associated with care engagement, excluding opioid substitution therapy visits, Complete case analysis ( $\mathrm{n}=$ 533) (Continued)

\begin{tabular}{ll}
\hline Variable & $\begin{array}{l}\text { Engaged } \mathrm{AOR}^{\mathrm{a}} \\
(95 \% \mathrm{Cl})\end{array}$ \\
\hline Yes & $1.01(0.58,1.73)$ \\
Other & ref \\
Overdose in the past 12 months & \\
Yes & $0.76(0.43,1.36)$ \\
Other & ref \\
Health characteristics & \\
Comorbid HIV & $1.09(0.45,2.64)$ \\
Yes & ref \\
No & use disorder $)$ \\
Mental health comorbidity (excluding substance & $3.43(2.19,5.38)$ \\
Yes & ref \\
No & \\
Reported last Hepatitis C test results & $1.20(0.71,2.01)$ \\
Positive & ref \\
Other & \\
Health care utilization & ref \\
Received support from peer worker & \\
Yes & \\
Other & \\
Ever on methadone & \\
Other & \\
\hline
\end{tabular}

${ }^{\mathrm{a}} \mathrm{AOR}=$ adjusted odds ratio, models adjusted for all listed covariates

settings [35]. Furthermore, while unstable housing is a known barrier to accessing primary care [36], those with stable housing and who have navigated the process of applying for disability are more likely to liaise with connected or co-located health care services, including mental health and addiction services [37], with such service integration being a key policy driver for improved care [38-41]. Finally, we found that even after excluding visits for opioid substitution therapy, PWUD receiving opioid substitution therapy were more likely to be engaged in primary care. This is consistent with our previous findings that receipt of methadone was associated with an approximately 50\% lowered risk of visiting an emergency department at least twice in a year [2], and likely reflects increased opportunities for care.

We used a community-based participatory research approach to gain rich survey data on a highly disadvantaged sample of PWUD. We linked this data to population-level data to characterize primary care engagement in a setting with universal health insurance. However, our study has limitations. Our survey relied on

Ever inject drugs 
self-reported data about practices that are highly stigmatized or illegal, which may have contributed to reporting biases. We used street-based peer recruitment to improve representativeness over standard recruitment methods [21, 42]; as such, our findings may not be widely generalizable to non-street based populations. To minimize the risk of sampling bias, we recruited a large sample using focused eligibility criteria, many different recruitment locations, and with multiple steps to make participation more accessible for our marginalized target population. In addition, ICES data cannot measure all visits to nurse practitioners, nurses, or other allied health professionals, thus engagement with primary care providers other than family physicians would not be captured. However, the number of nurse practitioners in Ontario is still relatively small (22.4 per 100,000 population in 2018) compared to the number of physicians $(236.5$ per 100,000$)$ [43]. Another potential limitation is that we chose one particular definition of engagement based on similar research in our region. Other definitions exist and may yield differing results. Thus, future studies may benefit from incorporating different definitions, as suitable to their objectives and health system contexts, or from incorporating sensitivity analyses comparing alternative definitions within a single study. Furthermore, as this is an observational study incorporating both survey data and health administrative data, we cannot infer a causal relationship between covariate and outcome. Our analysis of factors associated with primary care engagement may also be biased due to unmeasured confounders, such as personal beliefs about the value of health care. Similarly, the self-reported covariates were measured at only one time point. Future research intending to investigate these relationships should consider longitudinal study designs within a causal inference framework to assess the effects of changing social care and mental health care on primary care engagement. Finally, as patterns of polysubstance use are complex, distinguishing the associations between different patterns of substance use and primary care engagement was not within the scope of this study.

\section{Conclusions}

Our study demonstrated low engagement with a regular family physician among PWUD, reflecting known unmet health care needs among this population [8]. Considering the theoretical risk environment framework, our findings highlight the prominence of the policy environment [20], consistent with previous suggestions [35], as different policies often dictate who may access methadone, disability or income assistance, and housing support, and how they do so, and also affect access to mental health specialty care. Health care systems seeking to respond to the significant morbidity and acute care use among PWUD may benefit from incorporating primary carebased models $[39,40]$ that emphasize improved coordination and integration of opioid substitution therapy with other medical, mental health, and substance use care $[44,45]$. Such integration will require a commitment to overcome structural and philosophical barriers [46-48], with a focus on collaborative care that involves information continuity among providers, provider education, case management, and inclusion of the patient perspective $[47,49]$.

\section{Appendix}

Table 4 Ascertainment of mental health conditions (given the context of our cohort, we excluded substance use and alcohol use disorder which were included in the source definition) [26]

At least one hospitalization (CIHI-DAD or OMHRS) or ambulatory visit (NACRS) in the past 10 years with a diagnosis of ANY of the below diagnostic codes

$O R$

At least two visits in the past two years with a mental health diagnostic code $(\mathrm{OHIP})$

Mental health diagnostic (ICD-9) codes:

Psychotic Disorders

295 Schizophrenia

296 Manic-depressive psychoses, involutional melancholia

297 Other paranoid states

298 Other psychoses

Non-Psychotic Disorders

300 Anxiety neurosis, hysteria, neurasthenia, obsessive-compulsive neurosis, reactive depression

301 Personality disorders

302 Sexual deviations

306 Psychosomatic illness

309 Adjustment reaction

311 Depressive disorder

Social Problems

897 Economic problems

898 Marital difficulties

899 Parent-child problems

900 Problems with aged parents or in-laws

901 Family disruption/divorce

902 Education problems

904 Social maladjustment

905 Occupational problems

906 Legal problems

909 Other problems of social adjustment

Ascertainment of HIV [27]

3 physician claims (International Classification of Diseases, Ninth Revision (ICD-

9) code for HIV infection (042, 043, 044)) over a 3-year period (sensitivity and

specificity of $96.2 \%$ (95\% Cl $95.2-97.9 \%)$ and $99.6 \%$ (95\% Cl 99.1-99.8\%)) 


\section{Supplementary information}

Supplementary information accompanies this paper at https://doi.org/10. 1186/s12913-020-05670-z.

Additional file 1: Table S1. Adjusted multivariable logistic regression of PROUD participant characteristics associated with care engagement, excluding opioid substitution therapy visits. All participants $(n=663)$. Sensitivity analysis that collapsed all "no answer", "don't know" and missing responses with "no".

Additional file 2: Table S2. Adjusted multivariable logistic regression of PROUD participant characteristics associated with care engagement, including opioid substitution therapy visits. All participants $(n=663)$. Sensitivity analysis that included visits exclusively for opioid substitution therapy in the categorization of engagement status.

\section{Abbreviations}

PWUD: People who use drugs; PROUD: Participatory Research in Ottawa: Understanding Drugs; OHIP: Ontario Health Insurance Plan;

ADGs: Aggregated Diagnosis Groups

\section{Acknowledgements}

We are grateful to all PROUD participants and Community Advisory Committee members for their contributions to this research. The authors also thank Janessa Porter, Research Assistant, and Michael Fitzgerald, Research Writer, for help with formatting and revising the manuscript. The findings reported in this article were originally presented at the 28th Annual Canadian Conference on HIV/AIDS Research, Saskatoon, Saskatchewan, Canada in 2019 [50]

\section{Authors' contributions}

All authors made substantial contributions to the conception of this study at various phases. AM, DP, ND, BR, SL, MT led the acquisition of the data, and, along with $\mathrm{ZM}, \mathrm{RB}$ and $\mathrm{PO}$, substantially contributed to analysis and interpretation of the findings. CK, LB, JD and AB drafted the work. All authors read and approved the final manuscript and all authors have agreed both to be personally accountable for the author's own contributions and to ensure that questions related to the accuracy or integrity of any part of the work, even ones in which the author was not personally involved, are appropriately investigated, resolved, and the resolution documented in the literature.

\section{Funding}

This study was supported by ICES, which is funded by an annual grant from the Ontario Ministry of Health and Long-Term Care (MOHLTC). The opinions, results and conclusions reported in this article are those of the authors and are independent from the funding sources. No endorsement by ICES or the Ontario MOHLTC is intended or should be inferred.

We thank IMS Brogan Inc. for use of their Drug Information Database. Parts of this material are based on data and/or information compiled and provided by the Canadian Institute for Health Information (CIHI). However, the analyses, conclusions, opinions and statements expressed in the material are those of the author(s), and not necessarily those of $\mathrm{CIHI}$.

This project was also supported by grants from the Canadian Institutes of Health Research (CIHR) and the Ontario HIV Treatment Network (OHTN). Dr. Kendall was supported by a CIHR - OHTN New Investigator Award. Dr. Bayoumi was supported by the Fondation Baxter and Alma Ricard Chair in Inner City Health at St. Michael's Hospital and the University of Toronto. None of the funding bodies were involved in designing the study, data collection, analysis, interpretation of data, or writing the manuscript.

\section{Availability of data and materials}

The data set from this study is held securely in coded form at ICES. While data sharing agreements prohibit ICES from making the data set publicly available, access may be granted to those who meet pre-specified criteria for confidential access, available at www.ices.on.ca/DAS. The full data set creation plan and underlying analytic code are available from the authors upon request, understanding that the programs may rely upon coding templates or macros that are unique to ICES.

\section{Ethics approval and consent to participate}

This study received approval from the Ottawa Health Sciences Network Research Ethics Board (OHSN-REB \#20120566-01H). The use of administrative data in this project was authorized under section 45 of Ontario's Personal Health Information Protection Act, which does not require review by a Research Ethics Board. All participants included in the analyses provided written consent for linkage of their survey data to databases at ICES.

\section{Consent for publication}

Not applicable.

\section{Competing interests}

The authors declare that they have no competing interests.

\section{Author details}

${ }^{1}$ Bruyère Research Institute, 43 Bruyère Street, Annex E, Ottawa, Ontario K1N 5C8, Canada. ${ }^{2}$ CCES, Ottawa Hospital, Civic Campus, 1053 Carling Avenue, Box 684, Administrative Services Building, 1st Floor, Ottawa, Ontario K1Y 4E9, Canada. ${ }^{3}$ Somerset West Community Health Centre, 55 Eccles Street, Ottawa, Ontario K1R 6S3, Canada. ${ }^{4}$ RROUD Community Advisory Committee, Ottawa, Ontario, Canada. ${ }^{5}$ School of Social Work, McGill University, 3506 University Street, Room 421, Montreal, Quebec H3A 2A7, Canada. 'Sandy Hill Community Health Centre, 221 Nelson Street, Ottawa, Ontario K1N 1C7, Canada. ${ }^{7}$ Ottawa Public Health, 179 Clarence Street, Ottawa, Ontario K1N 1B3, Canada. ${ }^{8}$ Drug Users Advocacy League, Ottawa, Ontario, Canada. ${ }^{9}$ School of Population and Public Health, University of British Columbia, 2206 East Mall, Vancouver, British Columbia V6T 1Z3, Canada. ${ }^{10}$ MAP Centre for Urban Health Solutions, Li Ka Shing Knowledge Institute and Division of General Internal Medicine, St. Michael's Hospital; Department of Medicine and Institute of Health Policy, Management, and Evaluation, University of Toronto, 30 Bond Street, Toronto, Ontario M5B 1W8, Canada.

Received: 7 April 2020 Accepted: 19 August 2020

Published online: 07 September 2020

\section{References}

1. Degenhardt L, Whiteford HA, Ferrari AJ, Baxter AJ, Charlson FJ, Hall WD, et al. Global burden of disease attributable to illicit drug use and dependence: findings from the global burden of disease study 2010. Lancet. 2013;382(9904):1564-74.

2. Kendall C, Boucher L, Mark A, Martin A, Marshall Z, Boyd R, et al. A cohort study examining emergency department visits and hospital admissions among people who use drugs in Ottawa, Canada. Harm Reduct J. 2017; 14(16):1-10.

3. Walker ER, Pratt LA, Schoenborn CA, Druss BG. Excess mortality among people who report lifetime use of illegal drugs in the United States: a 20year follow-up of a nationally representative survey. Drug Alcohol Depend. 2017:171:31-8.

4. Mathers BM, Degenhardt L, Bucello C, Lemon J, Wiessing L, Hickman M. Systematic reviews mortality among people who inject drugs: a systematic review and meta-analysis. Bull World Heal Organ. 2013;91:102-23.

5. Millson P, Leonard L, Remis R, Strike C, Challacombe L. Injection drug use, HIV and HCV infection in Ontario- the evidence 1992-2004 [internet]. Ontario; 2004. Available from: http://www.ohrdp.ca/wp-content/uploads/2 013/05/Research_Report.pdf. Accessed 1 Feb 2019.

6. Boucher LM, Bayoumi AM, Mark AE, Cooper C, Martin A, Marshall Z, et al. Hepatitis $C$ testing, status and treatment among marginalized people who use drugs in an Inner City setting: an observational cohort study. Subst Use Misuse. 2019;54(1):18-30.

7. Beaulieu T, Ti L, Milloy M, Nosova E, Wood E, Hayashi K. Major depressive disorder and access to health services among people who use illicit drugs in Vancouver, Canada. Subst Abuse Treat Prev Policy. 2018;13(3):1-8.

8. Hyshka E, Anderson JT, Wild TC. Perceived unmet need and barriers to care amongst street-involved people who use illicit drugs. Drug Alcohol Rev. 2017:36:295-304.

9. Spithoff S, Kiran T, Khuu W, Kahan M, Guan Q, Tadrous M, et al. Quality of primary care among individuals receiving treatment for opioid use disorder. Can Fam Physician. 2019;65(5):343-51.

10. Kerr T, Wood E, Grafstein E, Ishida T, Shannon K, Lai C, et al. High rates of primary care and emergency department use among injection drug users in Vancouver. J Public Heal Vol. 2004;27(1):62-6. 
11. Palepu A, Tyndall MW, Leon H, Muller J, O'Shaughnessy MV, Schechter MT, et al. Hospital utilization and costs in a cohort of injection drug users. CMAJ. 2001; 165(4):415-20 Available from: http://www.pubmedcentral.nih.gov/articlerender. fcgi?artid=81365\&tool=pmcentrez\&rendertype=abstract. [cited 2014 Oct 17].

12. Dahrouge S, Devlin RA, Hogg B, Russell G, Coyle D, Fergusson D. The economic impact of improvements in primary healthcare performance. Ottawa: Canadian Health Services Research Foundation; 2012.

13. Starfield B. Primary care: an increasingly important contributor to effectiveness, equity, and efficiency of health services. SESPAS report 2012. Gac Sanit. 2012;26:20-6.

14. Stange KC, Ferrer RL. The paradox of primary care. Ann Fam Med. 2009;7(4): 293-9.

15. Starfield B, Shi L, Macinko J. Contribution of primary care to health systems and health. Milbank Q. 2005;83(3):457-502 Available from: http://www.ncbi. nlm.nih.gov/pubmed/16202000.

16. Lanoy E, Lewden C, Lièvre L, Tattevin P, Boileau J, Aouba A, et al. How does loss to follow-up influence cohort findings on HIV infection? A joint analysis of the French hospital database on HIV, Mortalité 2000 survey and death certificates. HIV Med. 2009;10(4):236-45.

17. Kim TW, Samet JH, Cheng DM, Winter MR, Safran DG, Saitz R. Primary care quality and addiction severity: a prospective cohort study. Health Serv Res. 2007:42(2):755-72.

18. Shi L, Starfield B, Politzer R, Regan J. Primary care, self-rated health, and reductions in social disparities in health. Heal Serv Res. 2002;37(3):529-50 Available from: http://www.ncbi.nlm.nih.gov/pubmed/12132594.

19. Ploeg J, Hayward L, Woodward C, Johnston R. A case study of a Canadian homelessness intervention programme for elderly people. Heal Soc Care Commun. 2008;16(6):593-605.

20. Rhodes T. The 'risk environment': a framework for understanding and reducing drug-related harm. Int J Drug Policy. 2002;13(2):85-94.

21. Lazarus L, Shaw A, LeBlanc S, Martin A, Marshall Z, Weersink K, et al. Establishing a community-based participatory research partnership among people who use drugs in Ottawa: the PROUD cohort study. Harm Reduct J [Internet]. 2014;11(26):1-8 Available from: http://www.ncbi.n/m.nih.gov/pmc/ articles/PMC4203893/.

22. Rhodes T. Risk environments and drug harms- a social science for harm reduction approach. Int J Drug Policy. 2009;20:193-201.

23. Shaw A, Lazarus L, Pantalone T, Leblanc S, Lin D, Stanley D, et al. Risk environments facing potential users of a supervised injection site in Ottawa , Canada. Harm Reduct J [Internet]. 2015;12(49):1-9. https://doi.org/10.1186/ s12954-015-0083-9.

24. Boucher L, Marshall Z, Martin A, Flynn JV, Lalonde C, Pineau D, et al. Expanding conceptualizations of harm reduction: results from a qualitative community-based participatory research study with people who inject drugs. Harm Reduct J. 2017;14:1-18.

25. The Johns Hopkins Adjusted Clinical Groups (ACG) System [Internet]. Johns Hopkins University Press; 1997. Available from: http://acg.jhsph.org/. Accessed 1 Feb 2019.

26. Steele LS, Glazier RH, Lin E, Evans M. Using administrative data to measure ambulatory mental health service provision in primary care. Med Care. 2004; 42(10):960-5.

27. Antoniou T, Zagorski B, Loutfy MR, Strike C, Glazier RH. Validation of casefinding algorithms derived from administrative data for identifying adults living with human immunodeficiency virus infection. PLoS One. 2011;6(6): e21748.

28. Glazier RH, Moineddin R, Agha MM, Zagorski B, Hall R, Manuel DG, et al. The impact of not having a primary care physician among people with chronic conditions. ICES investigative report. Toronto: Institute for Clinical Evaluative Sciences; 2008.

29. Kendall C, Boucher L, Donelle J, Martin A, Pineau D, Diliso N, et al. A cohort study of team-based care among marginalized people who use drugs in Ottawa, Canada (accepted). Can Fam Physician. 2019.

30. Sohler NL, Coleman SM, Cabral H, Naar-King S, Tobias C, Cunningham CO. Does self-report data on HIV primary care utilization agree with medical record data for socially marginalized populations in the United States? AIDS Patient Care STDS [Internet]. 2009;23(10):837-43 Available from: http://www. pubmedcentral.nih.gov/articlerender.fcgi?artid=2859764\&tool= pmcentrez\&rendertype=abstract.

31. Hwang SW, Chambers C, Katic M. Accuracy of Self-Reported Health Care Use in a Population-Based Sample of Homeless Adults. Health Serv Res. 2015;Early view:282-301. https://doi.org/10.1111/1475-6773.12329.
32. Cunningham CO, Li X, Ramsey K, Sohler NL. A comparison of HIV health services utilization measures in a marginalized population: self-report versus medical records. Med Care. 2007;45(3):264-8.

33. Davy Z. The promise of intersectionality theory in primary care [Internet]. [cited 2018 Oct 23]. Available from: http://primarycare.imedpub.com/thepromise-of-intersectionality-theory-in-primary-care.pdf.

34. Ross LE, Vigod S, Wishart J, Waese M, Spence JD, Oliver J, et al. Barriers and facilitators to primary care for people with mental health and/or substance use issues: a qualitative study. BMC Fam Pract. 2015;16:135.

35. Urada D, Teruya C, Gelberg L, Rawson R. Integration of substance use disorder services with primary care: health center surveys and qualitative interviews. Subst Abuse Treat Prev Policy. 2014;9:15.

36. Khandor E, Mason K, Chambers C, Rossiter K, Cowan L, Hwang SW. Access to primary health care among homeless adults in Toronto, Canada: results from the street health survey. Open Med. 2011;5(2):94-103.

37. Crowley RA, Kirschner N. The integration of Care for Mental Health, substance abuse, and other behavioral health conditions into primary care: executive summary of an American College of Physicians Position Paper. Ann Intern Med. 2015;163(4):298.

38. Milne R, Price M, Wallace B, Drost A, Haigh-Gidora I, Nezil FA, et al. From principles to practice: description of a novel equity-based HCV primary care treatment model for PWID. Int J Drug Policy. 2015;26(10):1020-7.

39. Rush B, Fogg B, Nadeau L, Furlong A. On the integration of mental health and substance use services and systems: summary report [internet]. 2008. Available from: http://www.ceca-cect.ca/pdf/Summary-reportFINAL-Dec1808.pdf. Accessed 1 Feb 2019.

40. Korthuis PT, McCarty D, Weimer M, Bougatsos C, Blazina I, Zakher B, et al. Primary care-based models for the treatment of opioid use disorder. Ann Intern Med. 2017;166(4):268.

41. Samet JH, Friedmann P, Saitz R. Benefits of linking primary medical care and substance abuse services. Arch Intern Med. 2001;161(1):85.

42. Broadhead RS, Heckathorn DD, Weakliem DL, Anthony DL, Madray H, Mills RJ, et al. Harnessing peer networks as an instrument for AIDS prevention: results from a peer-driven intervention. Public Health Rep. 1998;113 Suppl(Suppl 1):42-57.

43. Canadian Institute for Health Information. Canada's Health Care Providers, 2014 to 2018 - Data Tables. Ottawa: CIHI; 2020.

44. Islam MM, Topp L, Day CA, Dawson A, Conigrave KM. The accessibility, acceptability, health impact and cost implications of primary healthcare outlets that target injecting drug users: A narrative synthesis of literature. Int J Drug Policy. 2012;23(2):94-102.

45. Wilson T, Brar R, Sutherland C, Nolan S. Use of a primary care and pharmacy-based model for the delivery of injectable opioid agonist treatment for severe opioid use disorder: a case report. Can Med Assoc J. 2020;192(5):E115-7 Available from: http://www.cmaj.ca/lookup/doi/10.1503/ cmaj.190732.

46. Clark CD, Langkjaer S, Chinikamwala S, Joseph H, Semaan S, Clement J, et al. Providers' perspectives on program collaboration and service integration for persons who use drugs. J Behav Health Serv Res. 2017;44(1):158-67.

47. Savic M, Best D, Manning V, Lubman DI. Strategies to facilitate integrated care for people with alcohol and other drug problems: a systematic review. Subst Abuse Treat Prev Policy. 2017;12(1):19.

48. Storholm ED, Ober AJ, Hunter SB, Becker KM, lyiewuare PO, Pham C, et al. Barriers to integrating the continuum of care for opioid and alcohol use disorders in primary care: A qualitative longitudinal study. J Subst Abuse Treat. 2017;83:45-54 Available from: http://linkinghub.elsevier.com/retrieve/ pii/S0740547217302465. [cited 2018 Jul 12].

49. Olding M, Hayashi K, Pearce L, Bingham B, Buchholz M, Gregg D, et al. Developing a patient-reported experience questionnaire with and for people who use drugs: a community engagement process in Vancouver's downtown eastside. Int J Drug Policy. 2018:59:16-23.

50. Kendall C, Boucher LM, Bayoumi A, Donelle J, Martin A, Pineau D, et al. Engagement in primary health care among marginalized people who use drugs in Ottawa, Canada. In: 28th Annual Canadian Conference on HIV/AIDS Research - Abstracts. Saskatoon: CAHR; 2019. p. SS1.05.

\section{Publisher's Note}

Springer Nature remains neutral with regard to jurisdictional claims in published maps and institutional affiliations. 